\title{
MONETARY POLICY RULES IN PRACTICE: EVIDENCE FROM TURKEY
}

\author{
HAKAN BERUMENT ${ }^{1, *, \dagger}$ and HAKAN TAŞÇI ${ }^{2}$ \\ ${ }^{1}$ Department of Economics, Bilkent University, Ankara, Turkey \\ ${ }^{2}$ Department of Economics, University of North Carolina, Chapel Hill, NC 27599-3305, USA
}

\begin{abstract}
This paper estimates a forward-looking monetary policy reaction function of the Central Bank of the Republic of Turkey by considering the period from 1990:01 to 2000:10. When the spread between the interbank rate and depreciation rate of the local currency is taken as a policy tool, the empirical evidence suggests that the Turkish Central Bank responds to its foreign exchange reserves, output and M2 growth not the forward, current or lagged inflation. Copyright (C) 2003 John Wiley \& Sons, Ltd.
\end{abstract}

JEL CODE: E52; E58; F41

KEY wORDS: Inflation targeting; reaction function; spread

\section{INTRODUCTION}

After nearly a decade of high inflation, a number of important central banks began a concerted effort to rein in inflation during the 1980s. The net effect was the transition from a global environment, where inflation seemed a virtually intractable problem, to the current era, where the major economies of the world enjoy relative price stability. Therefore, inflation targeting has been implemented to some degree in some of the developed countries and several emerging markets to decrease and stabilize high inflation levels.

Clarida et al. (1998) assess how policy was conducted for the central banks of France, Germany, Italy, Japan, the UK and the US. For the three developed countries, Germany, Japan and the US, a forwardlooking inflation targeting has been witnessed. In addition, it appears that those central banks are inclined to have a watchful eye on the deviations of output from its long-run level.

While considering the developing countries with high chronic inflation, such as Turkey, the main targets of a central bank are not quite evident. The Central Bank of the Republic of Turkey (CBRT) openly declared that it has balance of payment as its policy objective but is also concerned with the stability of financial markets and inflation. Beginning in the early 1980s, by declaring or not declaring, CBRT targeted items on its balance sheet, such as net domestic assets or reserve money, as intermediate targets. Despite the recurring disinflationary stabilization programmes declared so far, it is evident that such programmes have not been successful.

With this inspiration, Berument and Malatyali (2000) identified the implicit reaction function of the CBRT within the period 1989:07 to 1997:08 by following the method of Clarida et al. (1998). Both of these papers followed Bernanke and Blinder (1992) while choosing the central bank's overnight interbank interest rate as their policy tool. The empirical evidence indicates that the CBRT responds to the lagged inflation

\footnotetext{
*Correspondence to: Hakan Berument, Department of Economics, Bilkent University, Ankara, Turkey.

${ }^{\dagger}$ E-mail: berument@bilkent.edu.tr
} 
rate rather than the future rate. M2 growth is targeted on an annual basis and output-targeting policy is implemented.

Berument (2004) states that central bankers of small open economies like Turkey have concerns like currency substitution and the level of foreign exchange reserves. Because of the high inflation and dollarization, agents choose to hold foreign currency to guard themselves against inflation, and the central bank may monitor the foreign reserves in order to eliminate the risk of speculative attack or a balance of payment crisis. In order to take these into account, he offers a new policy variable: the spread between the interbank interest rate and the currency depreciation. This paper assesses the role of the monetary policy by using the spread as the indicator of the central bank's policy tool.

Section 2 describes the specification. In Section 3, we describe our data set, estimation procedure and present the empirical evidence on this specification. Section 4 concludes our findings.

\section{METHODOLOGY}

Following Clarida et al. (1998), we specify the central bank's reaction function as

$$
s_{t}^{*}=s+\beta\left(E\left[\pi_{t+n} \mid \Omega_{t}\right]-\pi^{*}\right)+\gamma\left(E\left[y_{t} \mid \Omega_{t}\right]-y_{t}^{*}\right)
$$

where

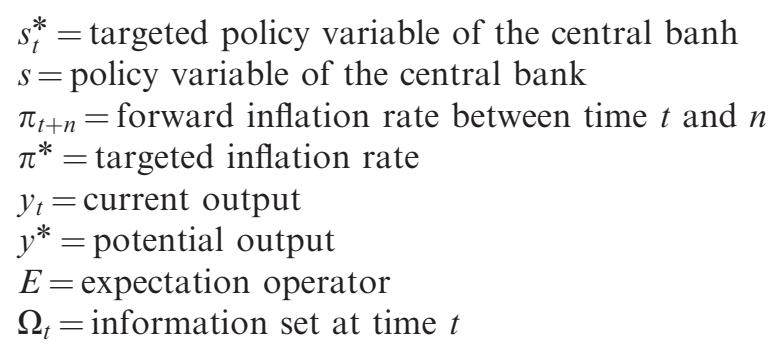

For the major central banks, the main operating instrument of monetary policy is a short-term interest rate (Sims, 1992). Goodfriend (1991) argues that even during the period of official reserve targeting, the central bank had in mind an implicit target for the interbank interest rate. Berument (2004) argues that for the Turkish case the spread between the interbank money market rate and the depreciation rate could be the indicator of the monetary policy of the CBRT due to the high inflation and dollarization. There is tradeoff between holding foreign exchange and domestic currency; the higher the interbank rate relative to foreign exchange, the higher the money demand. In order to tighten the economy, the CBRT increases the interbank rate relative to the depreciation of local currency. In this article, the spread is taken as the instrument variable of monetary policy.

In order to account for persistence or autocorrelation, we specify the following relationship for the actual spread:

$$
s_{t}=(1-\rho) s_{t}^{*}+\rho s_{t-1}+v_{t}
$$

where the error term $v_{t}$ is i.i.d. After this specification, combining the partial adjustment equation (2) and the target model (1) yields the policy reaction function. In this case, our model can be rewritten as follows:

$$
s_{t}=(1-\rho)\left(\alpha+\beta \pi_{t+n}+\gamma y_{t}\right)+\rho s_{t-1}+\varepsilon_{t}
$$

where

$$
\alpha=s-\beta \pi^{*} \quad \text { and } \quad \varepsilon_{t}=-(1-\rho)\left\{\beta \pi_{t+n}-E\left[\pi_{t+n} \mid \Omega_{t}\right]+\gamma\left(y_{t}-E\left[y_{t} \mid \Omega_{t}\right]\right)\right\}+v_{t}
$$

However, our specification is more general in this article. The role of other variables, such as exchange rates and net domestic assets, in the reaction function can be tested directly. In order to generalize this idea, we add a new vector of variables that the central bank might consider when setting up its monetary policy. 
Thus, our new model becomes:

$$
s_{t}=(1-\rho)\left(\alpha+\beta \pi_{t+n}+\gamma y_{t}+\psi z_{t}\right)+\rho s_{t-1}+\varepsilon_{t}
$$

Different lag orders of the spread are considered and lag order 2 works best for our sample. Therefore our specification takes the form:

$$
s_{t}=\left(1-\rho_{1}-\rho_{2}\right) s_{t}^{*}+\rho_{1} s_{t-1}+\rho_{2} s_{t-2}+v_{t} \quad \text { where } \quad\left|\rho_{1}+\rho_{2}\right|<1
$$

Substituting this specification in our model, the final model takes the form:

$$
s_{t}=\left(1-\rho_{1}-\rho_{2}\right)\left(\alpha+\beta \pi_{t+n}+\gamma y_{t}+\psi z_{t}\right)+\rho_{1} s_{t-1}+\rho_{2} s_{t-2}+\varepsilon_{t}
$$

This will be the model that we will use to assess the role of the monetary policy.

\section{DATA AND EMPIRICAL EVIDENCE}

In order to estimate the specification, we gathered data from monthly time series spanning the period from 1990:01 to 2000:10. ${ }^{1}$ All the data is taken from the electronic data delivery system of the CBRT. For the spread, we use the difference between the interbank overnight money market rate of the CBRT and the depreciation rate. Depreciation is the monthly logarithmic difference of the foreign currency basket of 1 US dollar and 1.5 Deutsche mark. Following Berument and Malatyali (2000), three types of inflation are defined. Three-monthly future inflation is defined as the three-month future difference of the logarithmic wholesale price index $\left[\pi_{t+3}=\log \left(w p i_{t+3}\right)-\log \left(w p i_{t}\right)\right]$, current inflation is the one-month lead difference $\left[\pi_{t}=\log \left(w p i_{t}\right)-\log \left(w p i_{t-1}\right)\right]$ and finally lagged inflation is the one-month lagged difference of the logarithmic price index $\left[\pi_{t-1}=\log \left(w p i_{t-1}\right)-\log \left(w p i_{t-2}\right)\right]$. Lastly, industrial production growth is seasonally adjusted.

In our model, since we include the future values of inflation and output deviation as regressors, the residual terms are no longer orthogonal to these values. Hence, OLS estimates will be biased. Therefore, following Clarida et al. (1998) and Berument and Malatyali (2000), we use Hansen's (1982) Generalized Method of Moments. ${ }^{2}$

In the baseline equation, the instrument set includes 12 lags of industrial production growth, inflation and spread. For our case, lag order 2 best fits our model for autocorrelation. Since the potential instrument set exceeds the parameter vector, the model is overidentified, so we test the overidentifying restrictions using the $J$-test (Hansen, 1982). Finally, in order to account for the effects of the 1994 self-inflicted financial crisis, additive dummies are introduced for each month of the period extending between 1994:03 and 1994:11.

The estimates of the implicit reaction function of the CBRT under different specifications are reported in Table 1. Column I reports the estimates of Taylor's (1993) specification. Both the estimated coefficients of output and target inflation are negative but statistically significant only for output. ${ }^{3}$ However, practices of monetary policy making suggest that spread is supposed to increase not decrease as the CBRT observes high inflation and growth. In order to hamper these two variables, they have to tighten the monetary policy.

Column II includes money growth (M2) and foreign reserves in the first specification. Adding M2 growth to the equation is a result of the central bank's role as liquidity provider. When there is a demand for liquidity by the public, the central bank provides this liquidity partially; sailing against the wind. Secondly, the uncovered interest rate parity condition suggests that higher domestic interest rates will increase the capital inflow; therefore, the CBRT may prefer to increase the spread to increase its reserves. Column II reports the estimates after these inclusions. The evidence suggests that the CBRT increases spread with higher inflation, output, M2 growth and foreign reserves as expected. The evidence on targeting reserves is statistically significant and the estimated coefficients for the output level and money growth are statistically significant at the margin. Thus, we took the specification in Column II as our baseline equation.

In Column III, we include short-term capital inflow growth in the specification to account for the possibility of the concern of the CBRT about short-term capital inflows. The slope coefficient is close to 

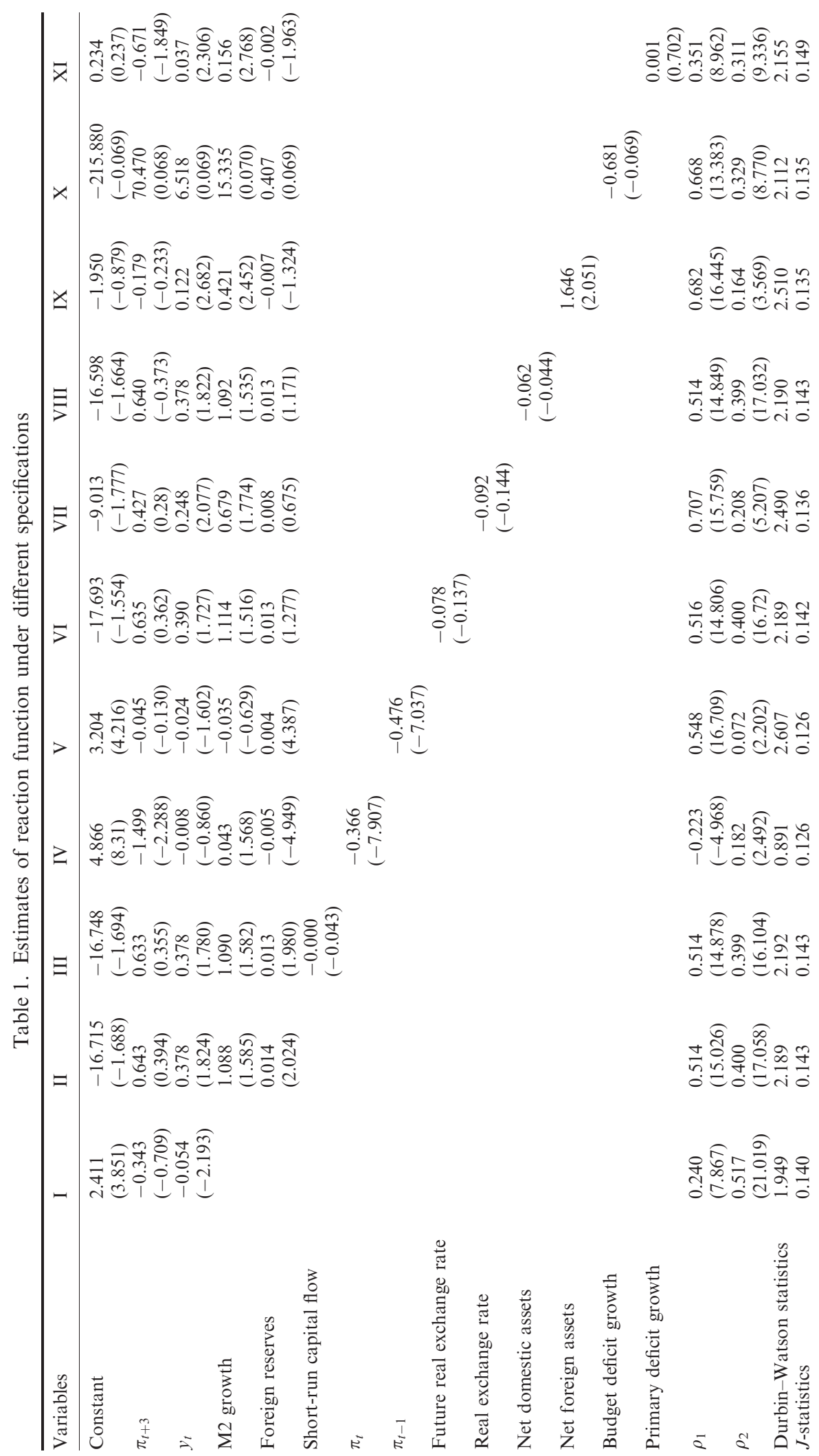
zero and statistically insignificant. This suggests that capital inflow was not an important concern for the CBRT in implementing its economic policy.

In order to account for other possible inflation timing concerns of the CBRT, we included the current and lagged values of inflation in the base equation. Both of them give results similar to the Taylor specification. The estimated coefficients of these inflation measures are statistically significant but negative. These negative coefficients are not what the tight monetary policy is supposed to suggest under high inflation.

The central bank officials argued that the CBRT had been targeting the real exchange rate for the sample period that we consider. In Columns VI and VII, future real exchange rate and current exchange rate are included in the specification. We include the real exchange rate as the log difference of the currency basket of 1 US dollar and 1.5 Deutsche mark and the wholesale price index. None of these added variables were statistically significant.

The CBRT also announced its Net Foreign Asset targets as part of the IMF-based stabilization programmes in order to overcome a possible payment crisis. In Columns VIII and IX, we included Net Domestic Asset and Net Foreign Asset targets in the specification in Column II. The estimated coefficient of the Net Domestic Assets in negative but statistically insignificant. When the Net Foreign Asset is included in the specification, it seems to give a positive and statistically significant coefficient. However, the DurbinWatson test statistics suggest that an autocorrelation problem exists for this case. Moreover, in this specification reserves become insignificant and have negative coefficients, which is the inverse of what we expected.

The final possible set of target variables that the CBRT may have is a budget deficit growth or a primary deficit growth. In Columns X and XI of the table, we performed the estimation by including the budget deficit growth and the primary deficit growth. Since the budget deficit includes the interest payments made in the general budget, we expect a positive relation between the spread and the budget deficit growth. In our case, the estimated coefficient is misleading; however, it is not statistically significant. For the primary deficit growth case, the effects of the interest payments are excluded, the coefficient of primary deficit growth is still statistically insignificant and has a very small slope coefficient. Therefore, we can exclude the effects of the primary deficit growth targeting from the reaction function.

One remark about the specifications that we employed in this paper is that the target inflation had no significant effect in any of the specifications. This concludes that in the Turkish case, inflation targeting is not a way that the CBRT chose to implement its monetary policy. Lastly, in all the different specifications tried above, the $J$-statistics, which test the overidentification restrictions, appear to be satisfactory. Hence the overidentifying restrictions cannot be rejected.

\section{CONCLUSION}

We have provided an empirical characterization of the systematic components of the implicit reaction function of the Central Bank of the Republic of Turkey by using the Turkish monthly data from 1990:01 to 2000:10. In order to do so, we have estimated a forward-looking policy reaction function. Spread is taken as the policy tool for the central bank. Our baseline specification includes money growth, industrial production, foreign reserves and target inflation as the regressors.

The empirical evidence indicates that the CBRT targeted neither the future inflation nor the lagged one. As a proxy of the national output, industrial production is a significant target of the CBRT at the margin. Reserves also have a significant and robust positive slope coefficient. Money growth is another target variable, though marginal. We can conclude that the CBRT is more concerned with the stability of the markets than inflation.

\section{NOTES}

1. The beginning of the sample is decided by the availability of the data and the end of the sample is determined to exclude the beginning of a period that includes a set of financial stress and crisis periods (see Berument, 2004). 
2. In order to apply GMM the series must be stationary. We perform Augmented Dickey-Fuller tests on the variables of interest. In all these series, we can reject the presence of unit roots for the sample used.

3. The level of significance is at $5 \%$, unless otherwise noted.

\section{REFERENCES}

Bernanke B, Blinder A. 1992. The federal funds rate and the channels of monetary transmission. American Economic Review 82: 901-921.

Berument H. 2004. Measuring monetary policy for a small open economy. Journal of Macroeconomics, forthcoming.

Berument H, Malatyali K. 2000. The implicit reaction function of the Central Bank of Republic of Turkey. Applied Economics Letters 7: $425-430$.

Clarida R, Gali J, Gertler M. 1998. Monetary policy rules in practice, some international evidence. European Economic Review 42: $1033-1067$.

Goodfriend M. 1991. Interest rate smoothing and the conduct of monetary policy. Carnegie-Rochester Conference on Public Policy 34: $7-30$.

Hansen L. 1982. Large sample properties of generalized method of moments estimators. Econometrica 50: $1029-1054$.

Sims C. 1992. Interpreting the macroeconomic time series facts. European Economic Review 36: 975-1011.

Taylor JB. 1993. Discretion versus policy rules in practice. Carnegie-Rochester Series on Public Policy XXIX: 195-214. 